\title{
Pemberian Buku Cerita Bergambar Bertema "Superhero" dapat Meningkatkan Pengetahuan Sayur dan Buah Siswa Sekolah Dasar
}

\author{
Indira Pradini ${ }^{1}$, Dudung Angkasa ${ }^{2 *}$, Idrus Jusat ${ }^{3}$, Lintang Purwara Dewanti ${ }^{4}$, Yulia Wahyuni $^{5}$ \\ 1,2,3,4,5 Program Studi Ilmu Gizi, Fakultas Ilmu-Ilmu Kesehatan, Universitas Esa Unggul \\ *email : dudung.angkasa@esaunggul.ac.id, Telp/HP. 0812-9893-3173
}

\section{ABSTRACT}

The low consumption of vegetables and fruit in school-age children is one of the unresolved nutritional problems in Indonesia. A way to improve vegetable and fruit eating behavior is to increase students' knowledge and attitudes through illustrated story book and heroic tales. The aim of this study is to find out the impact of picture books on students' knowledge and attitude. This is a quasy experimental study with Non equivalent control group with a pre-test and post-test which was followed by 97 fourth grade elementary school students including 41 students of intervention group and 56 students of control group. The mann-whitney test is used to see whether there are relationships between independent variable (given of illustrated story books) and the dependent variable (knowledge and attitude) between the intervention and control groups.The results showed a significant increase in knowledge and attitudes in the group which given illustrated story book. There were also significant differences in knowledge changes between the intervention and control groups. Illustrated story books can significantly increase students' knowledge about vegetables and fruit

Keywords : Knowledge; Attitudes; Vegetable; Fruits; Illustrated Story Book

\section{PENDAHULUAN}

Rendahnya konsumsi sayur dan buah pada anak usia sekolah merupakan masalah yang masih umum di Indonesia, padahal konsumsi sayur dan buah yang cukup, dapat mengurangi resiko anak usia sekolah untuk terkena obesitas(Ulilalbab, Anggraeni and LEstari, 2015) Didalam Pedoman Umum Gizi Seimbang, Kementrian Kesehatan Republik Indonesia menganjurkan konsumsi sayur dan buah harian adalah 3-4 porsi untuk sayur dan 2-3 porsi untuk buah(Kementrian Kesehatan RI, 2014) Sayur dan buah yang dikonsumsi dalam sehari juga harus berwarnawarni, manfaat sayur dan buah berdasarkan warna antara lain, warna merah untuk kesehatan jantung, warna oranye untuk kekebalan tubuh dan kesempurnaan deferensiasi sel, warna hijau untuk tulang dan gigi, warna biru dan ungu untuk daya ingat, dan warna putih dan coklat untuk kesehatan jantung dan darah(Suttie and Booth, 2011; Indriyanti et al., 2013; Robinson, 2016; Angkasa and Nadiyah, 2018) Dalam Riset Kesehatan Dasar tahun 2018 disebutkan bahwa proporsi konsumsi sayur dan buah dibawah 5 porsi masyarakat Indonesia diatas usia 5 tahun sebesar $95 \%$, sedangkan hanya 5\% warga Jakarta mengonsumsi sayur dan buah sesuai porsi setiap hari(Kementrian Kesehatan RI, 2018) Usaha untuk meningkatkan konsumsi sayur dan buah pada anak usia sekolah adalah dengan 
memberikan pendidikan gizi agar meningkatkan pengetahuan siswa tentang sayur dan buah. Untuk memudahkan penyampaian pesan pendidikan gizi, digunakan lah media sebagai alat bantu penyampai pesan. Buku cerita bergambar dinilai dapat digunakan sebagai salah satu alat bantu karena buku cerita bergambar menggabungkan antara tulisan, ilustrasi, dan keterampilan desain. Selain itu dengan buku cerita bergambar terjadi proses membolak-balik halaman ketika membaca(Bianquin and Sacchi, 2017) Dalam penelitian Tiara tahun 2019, dan Kusumarani tahun 2018 ditemukan bahwa pemberian buku cerita bergambar yang bertemakan kehidupan sehari-hari sebagai media pendidikan gizi dapat meningkatkan pengetahuan sayur dan buah siswa(Kusumarani, Noviardhi and Susiloretni, 2018; Tiara et al., 2019). Dari masalah diatas peneliti tertarik untuk membuat buku cerita bergambar dengan pendekatan tema "superhero" untuk meningkatkan ketertarikan siswa sehingga dapat meningkatkan pengetahuan tentang sayur dan buah.

\section{METODE PENELITIAN}

\section{BAHAN DAN METODE}

Jenis penelitian yang digunakan adalah Quassy Eksperimental dengan desain non equivalent control group. Penelitian ini dilakukan pada Tanggal 9-17 Desember 2019 di SDN Pulo Pagi dengan sampel 97 orang, yang terdiri dari 56 orang siswa kelas IV SDN Pulo 01, dan 05 Pagi sebagai kelompok kontrol dan 41 orang siswa kelas IV SDN Pulo 03 dan 09 Pagi sebagai kelompok intervensi. Perhitungan Sampel dilakukan dengan Aplikasi G*Power versi 3.1.9.4 dengan kriteria inklusi yaitu siswa yang bisa diajak berkomunikasi dengan baik dan mengikuti seluruh rangkaian penelitian, dan kriteria eksklusi siswa yang tidak mengikuti keseluruhan rangkaian penelitian.

Variabel yang diukur adalah pengetahuan dan sikap siswa. Pengukuran dilakukan dengan pengisian angket yang telah divalidasi terlebih dahulu (nilai r=0.90) yang terdiri dari 44 soal yang terdiri dari soal mewarnai, menyambung garis dan menjawab isian singkat, dan 20 pernyataan sikap. Penelitian dilakukan selama satu pekan dimulai dengan melakukan pre-test dan dilanjutkan dengan pembacaan buku cerita bergambar untuk kelompok intervensi dan penyuluhan dengan metode ceramah untuk kelompok kontrol. Gambar 1 meringkas alur pelaksanaan penelitian. Tim yang sudah diberikan pelatihan dan pengenalan prosedur penelitian diminta untuk memberikan ceramah selama 15-20 menit pada kelompok kontrol. Substansi materi yang disampaikan serupa dengan kelompok intervensi. 


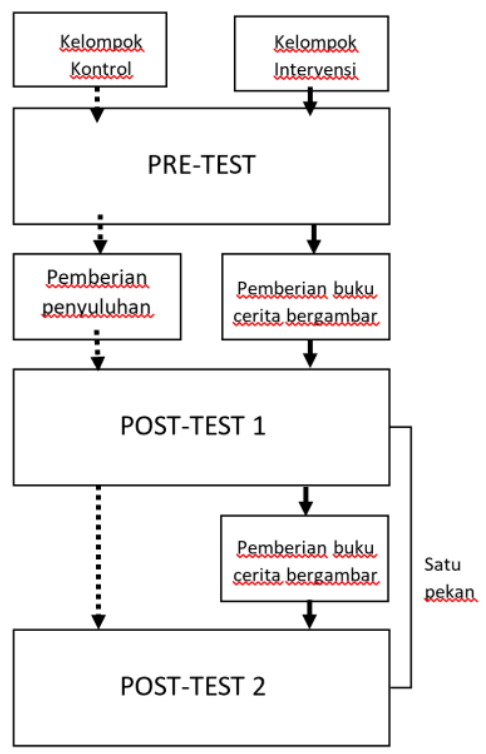

Gambar 1. Alur penelitian

Buku Cerita bergambar yang digunakan merupakan buku cerita berjudul "Rahasia Kapten Yassa: Sehat, Kuat dengan Sayur dan Buah" yang dikembangkan oleh Tim peneliti(Pradini, Angkasa and Jus'at, 2019) Buku cerita berisi kisah Kapten Yassa yang menjadi kuat dengan bantuan sayur dan buah. Setelah penyuluhan diberikan, kedua kelompok diberikan post-test pertama, selanjutnya kelompok intervensi diberikan buku untuk dibawa pulang dan dibaca dirumah selama satu pekan, sedangkan kelompok kontrol tidak diberikan apa-apa. Setelah satu pekan, dilaksanakan post-test kedua untuk kedua kelompok. Data yang diperoleh kemudian di uji dengan uji Mann-Whitney dan dependent T-Test. Penelitian ini telah diizinkan dengan persertujuan Komite Etik Universitas Esa Unggul Nomor: 0509-19.507/DPKEKEP/FINAL-EA/UEU/XI/2019.

\section{HASIL}

\section{Karakteristik Responden}

Jumlah siswa laki-laki dan perempuan pada kelompok intervensi hampir sama sedangkan pada kelompok kontrol lebih banyak siswa perempuan. Kelompok usia pada kelompok intervensi dan kontrol paling banyak yang usia nya sepuluh tahun

\section{Tabel 1. Karakteristik Siswa Sampel Penelitian $(\mathrm{n}=97)^{1}$}

\begin{tabular}{lcc}
\hline Variabel & $\begin{array}{c}\text { Intervensi } \\
\mathbf{n}(\%)\end{array}$ & Kontrol n(\%) \\
\hline Jenis & & \\
Kelamin & & \\
Laki-laki & $21(22 \%)$ & $25(26 \%)$ \\
Perempuan & $20(21 \%)$ & $31(32 \%)$ \\
Usia & & \\
9 & $15(15 \%)$ & $19(20 \%)$ \\
10 & $26(27 \%)$ & $36(37 \%)$ \\
11 & 0 & $1(1 \%)$
\end{tabular}

${ }^{1}$ Data disajikan dalam bentuk n(\%)

Analisis Bivariat

Tabel 2. Analisis bivariat yang dilakukan terhadap kelompok intervensi dan kontrol $(\mathrm{n}=97)^{1}$

Analisis bivariat yang dilakukan antara lain

\begin{tabular}{|c|c|c|c|c|}
\hline Variables & CG $(n=56)$ & IG $(n=41)$ & $\begin{array}{l}\text { Mean Diff } \\
(\text { CG-IG) })^{2}\end{array}$ & $\begin{array}{c}\text { p- } \\
\text { value }^{3}\end{array}$ \\
\hline \multicolumn{5}{|l|}{ Jenis Kelamin } \\
\hline Laki-laki & $25(26 \%)$ & $21(22 \%)$ & & \multirow{2}{*}{$0.522^{4}$} \\
\hline Perempuan & $31(32 \%)$ & $20(21 \%)$ & & \\
\hline Usia (tahun) & $9.68 \pm 0.51$ & $9.63 \pm 0.488$ & & $0.666^{5}$ \\
\hline & $19(20 \%)$ & $15(15 \%)$ & & \\
\hline & $36(37 \%)$ & $26(27 \%)$ & & \\
\hline 11 & $1(1 \%)$ & 0 & & \\
\hline \multicolumn{5}{|l|}{ Pengetahuan $^{6}$, score } \\
\hline Pre-test (PT0) & $72.44 \pm 9.97$ & $67.29 \pm 10.26$ & $5.15 \pm 2.08$ & $0.015^{5}$ \\
\hline Post-test 1 (PT1) & $74.63 \pm 9.8$ & $67.63 \pm 11.36$ & $7.00 \pm 2.15$ & 0.001 \\
\hline Post-test 2 (PT2) & $77.15 \pm 9.84$ & $78.16 \pm 10.3$ & $-1.01 \pm 2.04$ & 0.424 \\
\hline Changel (PT1-PT0) & $2.19 \pm 7.32$ & $0.33 \pm 6.54$ & $1.86 \pm 1.44$ & $0.199^{5}$ \\
\hline Change 2 (PT2-PT0) & $4.71 \pm 10.55$ & $10.86 \pm 7.70$ & $-6.15 \pm 1.94$ & $0.002^{5}$ \\
\hline p-value PT1 vs PT0 & $0.029^{8}$ & $0.746^{8}$ & & \\
\hline p-value PT2 vs PT0 & $0.002^{8}$ & $0.0001^{8}$ & & \\
\hline \multicolumn{5}{|l|}{ Sikap ${ }^{7}$, score } \\
\hline Pre-test (PT0) & $77.85 \pm 15.69$ & $67.07 \pm 24.29$ & $10.78 \pm 4.06$ & 0.040 \\
\hline Post-test 1 (PT1) & $85.17 \pm 17.26$ & $76.95 \pm 21.24$ & $8.22 \pm 3.91$ & 0.092 \\
\hline Post-test 2 (PT2) & $89.11 \pm 15.16$ & $82.8 \pm 18.56$ & $6.31 \pm 3.43$ & 0.037 \\
\hline Change 1 (PT1-PT0) & $7.23 \pm 15.31$ & $9.88 \pm 21.77$ & $-2.65 \pm 3.76$ & $0.499^{5}$ \\
\hline Change 2 (PT2-PT0) & $11.26 \pm 15.58$ & $\begin{array}{c}15.73 \pm \\
24.68\end{array}$ & & \multirow[t]{3}{*}{$0.277^{5}$} \\
\hline p-value PT1 vs PT0 & $0.001^{8}$ & $0.006^{8}$ & & \\
\hline p-value PT2 vs PT0 & $0.0001^{8}$ & $0.0001^{8}$ & & \\
\hline \multicolumn{5}{|c|}{$\begin{array}{l}\text { Keterangan: }{ }^{1} \text { Data disajikan dalam bentuk mean } \pm \text { Std. Deviasi; }{ }^{2} \text { Disajikan dalam } \\
\text { mean differencetstd, error; }{ }^{3} \text { Merupakan nilai signifikansi Mann-Whitney; } \\
{ }^{4} \text { Merupakan nilai pearson chi-square. }{ }^{5} \text { Merupakan nilai independent T-Test; } \\
{ }^{6} \text { Skor pengetahuan didapatkan dengan menjawab } 44 \text { pertanyaan yang meliputi } \\
\text { kesesuaian warna dan jenis sayur dan buah, porsi sehari konsumsi sayur dan buah, } \\
\text { manfaat umum konsumsi sayur dan buah, dan manfaat sayur dan buah berdasarkan } \\
\text { warna; }{ }^{7} \text { Skor sikap didapatkan dari menjawab } 10 \text { pernyataan positif dan } \\
10 \text { pernvataan negative: }{ }^{8} \text { Merupakan nilai dependent T-Test: }\end{array}$} \\
\hline
\end{tabular}

adalah jenis kelamin, usia, pengetahuan dan sikap terhadap masing-masing kelompok. Hasil analisis 
bivariat terangkum dalam Tabel 3 dibawah ini.

Terdapat peningkatan pengetahuan yang signifikan antara PT0 dengan PT1 dan PT0 dengan PT2 pada kelompok kontrol dan juga antara PT0 dengan PT2 kelompok intervensi. Nilai skor pengetahuan pada PT0 dan PT1 antara kelompok intervensi dan kelompok kontrol memiliki perbedaan yang signifikan. Namun, pada PT2 tidak terdapat pengetahuan yang signifikan antara kelompok intervensi dan kelompok kontrol. Perubahan Skor pengetahuan dapat dilihat pada grafik dibawah ini

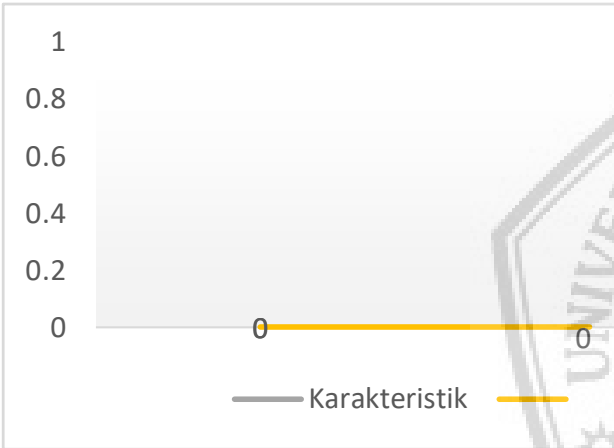

Gambar 2. Perubahan Skor Pengetahuan Antara Kelompok Intervensi dan Kelompok Kontrol

Terdapat peningkatan skor sikap yang signifikan pada kelompok kontrol maupun kelompok intervensi, namun tidak terlihat ada perbedaan yang signifikan antara kelompok intervensi dan kelompok kontrol.

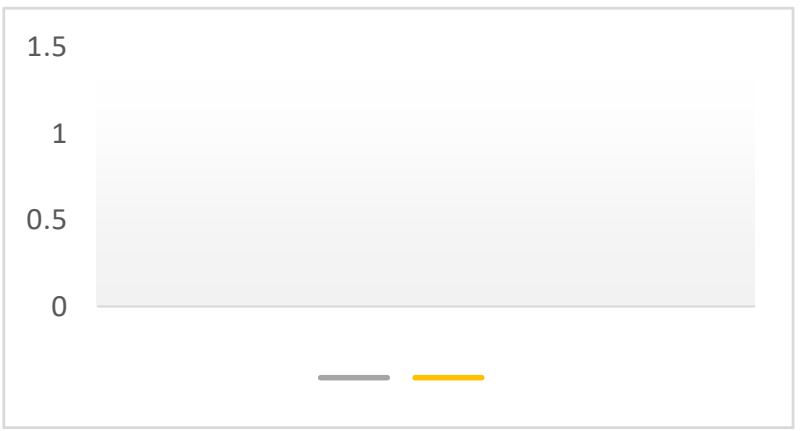

Gambar 3. Perubahan Skor Pengetahuan Antara Kelompok Intervensi dan Kelompok Kontrol

\section{PEMBAHASAN \\ Perubahan Pengetahuan}

Pada kelompok intervensi, terjadi kenaikan nilai rata-rata yang tidak signifikan pada PT0 dengan PT1. Pada PT2 terdapat perubahan yang signifikan dari pre-test, sehingga hasilnya sesuai dengan yang diharapkan, yaitu adanya peningkatan nilai pengetahuan antara sebelum dan sesudah pemberian media buku cerita bergambar. Kenaikan nilai pengetahuan ini berarti buku cerita bergambar yang diberikan pada kelompok intervensi dapat meningkatkan pengetahuan siswa. Hal ini sejalan dengan penelitian Romadhoni, dkk. yang dilakukan pada siswa sekolah dasar dengan pemberian intervensi selama 60 menit(Romadhoni, Hartini and Oktasari, 2018) menunjukan hasil bahwa buku komik/cerita bergambar dapat meningkatkan pengetahuan sampel. Peningkatan pengetahuan yang signifikan nilainya dengan beda sepuluh poin antara PT0 dan PT2 mungkin terjadi karena buku cerita diberikan memiliki alur cerita yang lebih menarik, yaitu mengangkat tokoh cerita yang merupakan pahlawan hal ini dibandingkan dengan penelitian Tiara yang isi buku ceritanya merupakan cerita kehidupan sehari-hari. Kenaikan yang signifikan pada kelompok intervensi ada pada soal pengetahuan nomor tentang warna, jenis, dan menarik garis sayur dan buah, tentang buah warna hijau sesuai fungsi, tentang sayur warna merah sesuai fungsi, tentang total porsi sayur, dan tentang total porsi buah(Tiara et al., 2019). Penelitian ini juga sejalan dengan penelitian Syiva yang menggunakan 
media permainan untuk meningkatkan pengetahuan siswa, media permainan berhasil meningkatkan pengetahuan dengan melibatkan empat alat indera untuk menerima pesan yang disampaikan dan berhasil meningkatkan pengetahuan sebesar 24 poin, sedangkan media buku cerita bergambar yang melibatkan tiga alat indera meningkatkan pengetahuan sebesar 11 poin(Faridah, Sitoayu and Nuzrina, 2019). Hal ini wajar terjadi karena semakin banyak alat indera yang digunakan semakin banyak pengetahuan yang diterima, semakin besar pula peningkatan skor yang akan didapatkan, sesuai dengan definisi pengetahuan yang merupakan hasil tahu dari proses penginderaan terhadap sesuatu(Notoatmodjo, 2003; Angkasa et al., 2017). Kenaikan yang tidak signifikan antara PT0 dengan PT1 kemungkinan terjadi karena anakanak sudah merasa lelah, dan bosan harus mengerjakan soal kembali setelah pembacaan cerita sehingga hanya beberapa yang menjawab soal sesuai dengan apa yang sudah dijelaskan. Namun bila dilihat dari antusiasme siswa pada pembacaan cerita hampir semua anak semangat dan mengerti pesan yang disampaikan didalam cerita.

Pada kelompok kontrol, terdapat perubahan skor pengetahuan yang signifikan antara rata-rata PT0 dan PT1 dan PT2. Antara PT0 dengan PT1 terdapat perbedaan 2 poin lebih tinggi, sedangkan untuk PT2 dengan pre-test terdapat perbedaan 4 poin lebih tinggi. Hal ini sejalan dengan penelitian Kusumarani, dkk yang kelompok kontrolnya sama-sama murid Sekolah Dasar Negeri dan Jurnal Gizi Unimus Vol 10 No 12021 diberikan ceramah menunjukan hasil bahwa kelompok kontrol yang hanya diberi ceramah juga meningkatkan nilai pengetahuan siswa(Kusumarani, Noviardhi and Susiloretni, 2018). Hal ini dapat terjadi karena antusias sampel dari kelompok kontrol sangat tinggi sehingga terjadilah peningkatan pengetahuan. Perubahan nilai pengetahuan kelompok kontrol mengalami peningkatan yang signifikan ada pada soal tentang apakah terong adalah sayur, tentang sayur warna merah sesuai fungsi, tentang total porsi sayur, dan tentang warna-warni sayur gambar ketiga. Hal ini juga terjadi pada penelitian Dahniman, terdapat peningkatan pengetahuan pada kelompok kontrol yang diberikan media leaflet(Saputra, Nuzrina and Wahyuni, 2016).

Terdapat perbedaan yang signifikan pada PT0 dan PT1 antara kedua kelompok. Tetapi perubahan skor (PT1-PT0) pada kelompok kontrol lebih tinggi dari pada skor kelompok intervensi. Pada PT2 antara kelompok intervensi dan kelompok kontrol tidak menunjukan perbedaan yang nyata. Bila kita lihat perubahan pertama dari pre-test dengan PT1 hasil yang didapatkan masih tidak signifikan, namun pada perbedaan antara pre-test dengan PT2 terdapat berbedaan yang signifikan. Hal ini sejalan dengan penelitian Tiara, dkk yang hasilnya media buku cerita bergambar dapat meningkatkan pengetahuan siswa karena terdapat perbedaan nilai rata-rata yang signifikan antara kelompok intervensi dan kelompok kontrol(Tiara et al., 2019). Pada penelitian Tiara yang dilakukan kepada siswa sekolah dasar juga selisih antara nilai pengetahuan PT0 dengan PT2 dari kelompok 
kontrol dan intervensi lebih tinggi 0.6 poin dari pada penelitian ini. Perbedaan ini bisa jadi disebabkan oleh pembacaan cerita yang dilakukan Tiara, dkk sebanyak dua kali, selain itu anak juga di iming-imingi hadiah agar mau membaca buku dirumah(Tiara et al., 2019)

\section{Perubahan Sikap}

Terdapat perubahan yang signifikan antara rata-rata PT0 dengan PT1 dan PT0 dengan PT2 pada kelompok intervensi. Antara PT0 dengan PT1 terdapat perbedaan 9 poin lebih tinggi, sedangkan untuk PT0 dengan PT2 terdapat perbedaan 15 poin lebih tinggi, sehingga hasilnya sesuai dengan yang diharapkan, yaitu adanya peningkatan nilai sikap antara sebelum dan sesudah pemberian media buku cerita bergambar. Hal ini tidak sejalan dengan/penelitian Kusumarani, dkk yang menunjukan tidak adanya perubahan sikap dengan pemberian intervensi(Kusumarani, Noviardhi and Susiloretni, 2018). Namun bila dilihat lebih detail tentang mekanisme pemberian, walaupun samasama diberi intervensi untuk membaca selama satu pekan, tidak ada pembacaan buku bersama sebelumnya setelah pre-test berlangsung. Tema cerita yang diusung juga hanya terkait dengan kehidupan sehari-hari. berbeda dengan buku cerita Kapten Yassa pada penelitian ini yang mengusung tema pahlawan yang menjadi ketertarikan tersendiri bagi anak-anak.

Pada sikap kelompok kontrol, terdapat perubahan yang signifikan juga antara rata-rata PT0 dengan PT1 dan antara PT0 dengan PT2.
Antara PT0 dengan PT1 terdapat perbedaan 7 poin lebih tinggi, sedangkan untuk PT0 dengan PT2 terdapat perbedaan 11 poin lebih tinggi. Hal ini tidak sejalan dengan penelitian Anggraeni, dkk yang dalam penelitiannya disebutkan bahwa ceramah tidak bisa meningkatkan sikap kelompok kontrol(Enggar Anggraeni, Didik Gunawan Tamtomo, 2014). Hal seperti penelitian Anggraeni tersebut dapat terjadi apabila situasi kelas tidak kondusif, namun pada penelitian ini, sebagian besar siswa di kelompok kontrol tertarik untuk mendengarkan ceramah yang dikemas sedemikian rupa dan terdapat sesi tanya jawab di akhir dan mendapat respon pertanyaan yang luar biasa dari anak-anak. Penelitian lain tetapi menggunakan media yang berbeda yaitu video game(Angkasa, Pratiwi and Jus' at, 2020) juga turut menunjukkan hasil serupa yaitu perbaikan sikap siswa setelah diberikan edukasi. Walau medianya berbeda tetapi kesamaan yang dapat menjadikan perubahan sikap ialah selain banyaknya indera (senses) yang terlibat, diskusi dapat terjadi pada sesama siswa yang membaca komik. Diskusi merupakan salah satu cara efektif untuk internalisasi nilai dari pengetahuan yang didapat. Apalagi cerita bergambar Kapten Yassa ini dilengkapi latihan berupa permainan pada bagian akhir buku.

\section{KESIMPULAN}

Terdapat peningkatan pengetahuan yang signifikan pada kelompok yang diberikan buku cerita bergambar sebagai media pendidikan gizi. Terdapat juga perbedaan pengetahuan yang 
signifikan antara kelompok intervensi setelah satu pekan diberikan media buku cerita bergambar bertema superhero. Saran untuk peneliti berikutnya dapat diadakan lembar monitoring untuk memastikan berapa kali siswa membaca buku dirumah. Peneliti berikutnya juga hendaknya mengkondisikan anak-anak agar lebih tertib saat dikelas.

\section{UCAPAN TERIMA KASIH}

Terimakasih atas dukungan Orang tua, Guru-guru dan Siswa/I SDN Pulo 01, 03, 05, 09 Pagi atas partisipasi aktifnya dan kerjasama yang baik selama penelitian. Terimakasih kepada GISEL Project(Angkasa and Nadiyah, 2018) atas inspirasinya dalam inisiasi Rahasia Kapten Yassa edisi pertama. Terimakasih pada PT.Indofood CBP Sukses Makmur TBK yang telah memberikan dukungan finansial dalam perbanyakan buku Rahasia Kapten Yassa.

Manuskrip ini telah diikutkan pada Scientific Article Writing Training (SAWT) Batch II, Program Kerja GREAT 4.1.e, Program Studi S1 Gizi, FIKES, Universitas Esa Unggul dengan dukungan fasilitator: Dudung Angkasa, SGz., M.Gizi, RD; Khairizka Citra Palupi, SGz., MS; Laras Sitoayu, SGz., MKM, RD. SAWT Batch II juga mendapat dukungan dana dari Universitas Esa Unggul(Angkasa et al., 2020).

\section{DAFTAR PUSTAKA}

Angkasa, D. et al. (2017) 'Peduli Sarapan Dan Makanan Sehat, Serta Higiene Dan Sanitasi Lingungan Sekolah Pada Siswa Sekolah Dasar Di Kecamatan Sepatan Timur', Jurnal Abdimas.
Angkasa, D. et al. (2020) Program Kerja U GO GREAT. Jakarta: Perpustakaan Universitas Esa Unggul. Available at: https://digilib.esaunggul.ac.id/program-kerja-ugo-great-program-studi-s1-ilmu-gizi17032.html.

Angkasa, D. and Nadiyah (2018) Jelajah Guna dan Pelangi Makanan Bersama Gisel dan Kawan-Kawan: Seri 1. Jakarta.

Angkasa, D., Pratiwi, R. A. and Jus' at, I. (2020) "MAPAGI" video game upgraded breakfast attitude among urban elementary school children in West Jakarta, Indonesia', Malaysian Journal of Nutrition, 26(3), pp. 341-351. doi: https://doi.org/10.31246/mjn-2019-0127.

Bianquin, N. and Sacchi, F. (2017) 'More than Just Pictures: Using Picture Books to Broaden Young Learners' Disability Understanding', Proceedings, 1(9), p. $890 . \quad$ doi: 10.3390/proceedings 1090890 .

Enggar Anggraeni, Didik Gunawan Tamtomo, D. H. (2014) 'Perbedaan Pengaruh Pelajaran Gizi Menggunakan Media Animasi Dan Ceramah Terhadap Pengetahuan Gizi, Sikap Dan Perilaku Konsumsi Buah Dan Sayur Pada Anak Sekolah Dasar', Jurnal Gizi dan Kesehatan, 1(2).

Faridah, S. N., Sitoayu, L. and Nuzrina, R. (2019) 'Efektivitas Veggie-Fruit Dart Game terhadap Konsumsi Sayur dan Buah pada Siswa SDN Duri Kepa 05 PG', Indonesian Journal of Human Nutrition, 6(1), pp. 22-31.

Indriyanti, W. et al. (2013) 'Solusi Cerdas Diet Therapy Jantung Berbasis Buah Dan Sayuran Lokal', Jurnal Online Nutrisains, pp. 1-13.

Kementrian Kesehatan RI (2014) Pedoman Gizi Seimbang, Kementrian Kesehatan RI.

Kementrian Kesehatan RI (2018) Hasil Utama Riskesdas 2018. doi: 1 Desember 2013.

Kusumarani, A., Noviardhi, A. and Susiloretni, K. A. (2018) 'Pengaruh Media Komik Terhadap 
Pengetahuan Dan Sikap Tentang Sayur Dan Buah Di Sd Aisyiyah Dan Sdn Kalicilik 2 Demak', Jurnal Riset Gizi, 6(2), p. 46. doi: 10.31983/jrg.v6i2.4311.

Notoatmodjo, S. (2003) Pendidikan dan Perilaku Kesehatan. Jakarta: Rineka Cipta.

Pradini, I., Angkasa, D. and Jus'at, I. (2019) Rahasia Kapten Yassa: Sehat, Kuat dengan Sayur dan Buah. Jakarta.

Robinson, J. G. (2016) What Color is Your Food. North Dakota State University. doi: 10.1016/0167-4048(95)96999-j.

Romadhoni, I., Hartini, Th. N. S. and Oktasari, R. (2018) Pengaruh Pemberian Media Buku Cerita Bergambar Terhadap Peningkatan Pengetahuan Sayur Dan Buah Pada Siswa Sekolah Dasar, Skripsi. Poltekkes Kemenkes Yogyakarta.
Saputra, M. D., Nuzrina, R. and Wahyuni, Y. (2016) Pengaruh Pemberian Edukasi Gizi Melalui Media Video dan Leaflet terhadap Perubahan Konsumsi Buah dan Sayur pada Siswa SMP Al Chasanah Tahun 2016. Jakarta.

Suttie, J. W. and Booth, S. L. (2011) 'Vitamin K', American Society for Nutrition, 2, pp. 440-441. doi: 10.3945/an.111.000786.vitamin.

Tiara, D. N. et al. (2019) 'Pendidikan gizi menggunakan cerita bergambar terhadap pengetahuan dan frekuensi konsumsi sayur buah pada siswa', Jurnal Riset Kesehatan, 11(1), pp. 165-172.

Ulilalbab, A., Anggraeni, E. and LEstari, I. A. (2015) Obesitas Anak Usia Sekolah. Yogyakarta: Deepublish Publisher 